\title{
Clinical outcome of closed reduction of cervical spine injuries in a cohort of Nigerians
}

\author{
Augustine Abiodun Adeolu, ${ }^{1,2}$ Alvan-Emeka Kelechi Ukachukwu $\mathbb{1 0}^{2} \cdot$ Josephine Oluwayemisi Adeolu ${ }^{3}$. \\ Amos Olufemi Adeleye ${ }^{1,2} \cdot$ Godwin Inalegwu Ogbole ${ }^{4} \cdot$ Adefolarin Obanishola Malomo $^{1,2}$. \\ Matthew Temitayo Shokunbi ${ }^{1,2}$
}

Received: 4 October 2018 / Revised: 23 January 2019 / Accepted: 23 January 2019

(C) International Spinal Cord Society 2019

\begin{abstract}
Study design A prospective observational study.

Objectives To evaluate the effectiveness of closed reduction of cervical spine injuries (CSIs) using cervical traction and identify probable complications.

Setting Department of Neurological Surgery, University College Hospital, Ibadan, Nigeria.

Methods Consecutive CSIs managed by closed reduction using Gardener-Well's Tongs traction were prospectively analysed. The data included imaging and neurological examinations findings, Frankel grading, and extent of reduction. Reduction of $95 \%$ or more was deemed satisfactory. The primary outcome measures were extent/degree of reduction and neurologic status classified as improved, same, or worse. Other complications were taken as secondary outcome measures. Result Seventy-four patients, 49 males, mean age 35.2 years (SD 9.7) were included. In all, $78.4 \%$ presented within 72 hours of injury. In total, $85.1 \%$ had road traffic crashes. Anterior subluxation was seen in $86.5 \%$. The degree of displacement was $<25 \%$ in $36 / 74$ (48.6\%), $25-50 \%$ in $19 / 74$ (25.7\%), $50-75 \%$ in $8 / 74$ (10.8\%), and $>75 \%$ in $11 / 74$ (14.9\%). Traction reduction was done after 7 days of injury in $52.7 \%$ and same day of injury in $1.4 \%$. Reduction weight ranged from $2 \mathrm{~kg}$ to $60 \mathrm{~kg}$. Reduction was satisfactory in $67.6 \%$ and failed in $32.4 \%$. In all, $81.1 \%$ of patients remained neurologically the same, while $18.9 \%$ improved. Causes of failed reduction were facet lock (15), old injury (8), new-onset/worsening pain (3), and over-distraction (2). Complications of closed reduction were over-distraction (5), tong pull-out (2), new-onset/worsening pain (2), and skull perforation (1).
\end{abstract}

Conclusions Satisfactory closed reduction is feasible in patients with CSI and significant malalignment. The method is associated with few complications.

Alvan-Emeka Kelechi Ukachukwu

dr_alvan@yahoo.com

1 Department of Surgery, College of Medicine, University of Ibadan, Ibadan, Nigeria

2 Department of Neurological Surgery, University College Hospital, Ibadan, Nigeria

3 Department of Community Medicine, University College Hospital, Ibadan, Nigeria

4 Department of Radiology, College of Medicine, University of Ibadan, and University College Hospital, Ibadan, Nigeria

\section{Introduction}

The cervical spine is the most vulnerable and most frequently injured portion of the vertebral column because of its high degree of mobility [1-3]. Injuries follow high velocity trauma in road traffic collisions, falls, sports and diving accidents, while disruption of spinal alignment arises from hyperflexion, hyperextension, and axial loading forces with or without accompanying rotation $[1,2,4]$. The malalignment can be due to subluxations and distractions of the various cervical joints or/and fractures involving the cervical bones. The neurologic injuries may be complete or incomplete with potential for recovery based upon degree of injury.

In order to prevent further neurologic injury from instability and continuous neuronal compression, it is 
pertinent to reduce or realign the cervical spine $[5,6]$. This provides the optimal condition for healing and recovery of neurologic functions. The most effective means of initial reduction and management of cervical spine injuries (CSIs) is controversial [7]. Many studies favour early and rapid aggressive reduction while others disagree especially in complete injuries. Current guidelines indicate that early reduction improves neurologic outcome by restoring anatomic alignment and canal diameter, and decompressing the cervical spinal cord $[4,5,8]$.

Reduction may be by open (operative) or closed (nonoperative) means. Both may be applied in some instances. Surgery for injuries with neurological deficits is promoted as the standard of choice, but this is debated by some clinicians who query the scientific basis for the decision, the proof of clinical benefit, and the role of expanding technical possibilities and approval of implant usage by regulatory bodies [9]. The arguments against surgical decompression and/or fixation include the risks of secondary trauma during surgery, risks of early mobilisation, delays in reaching a trauma centre where an experienced surgeon is available, and the unclear decision between long segment and short segment/minimally invasive procedures [9]. These arguments have projected the excellent neurologic outcomes that follow conservative management (including traction use), which require simultaneous attention to the injured spine and other body systems in a recumbent position for up to 4-6 weeks post trauma [10]. No evidence suggests that surgical realignment and stabilisation or deformity correction or decompression achieves equal or superior outcomes to conservative care, and the opinion that surgery gives better neurological outcomes in incomplete injuries do not consider that neurological recovery may be better if no surgical intervention is carried out [10].

Non-operative or closed reduction is simple, efficient, quick, cheap, reliable, and safe [6, 11-14]. It was first described by Walton in 1893, and expounded by Crutchfield who introduced special tongs for in-line traction in 1933 while Evans and Kleyn popularised reduction under anaesthesia [5, 11, 15]. Closed reduction using continuous axial traction is advocated in the conscious patient before stabilisation through operative fixation $[5,16]$. The methods of closed reduction in current use include manipulation under anaesthesia (MUA), Halter traction, Halo traction and Skull tong (Crutchfield or Gardener-Wells tongs (GWTs)) traction $[1,2,4,5,7,11-16]$. Skull tongs are cheap and provide a firm grip on the skull; and skull tong traction is commonly used in low-income settings like Nigeria.

Closed traction reduction is usually monitored using bedside fluoroscopy, magnetic resonance imaging (MRI), or simple X-ray guidance $[4,5,13]$. No consensus exists on the initial reduction weight, maximal reduction weight, and maintenance weight $[7,12]$. Some authors begin with a 3-pound $(1.4 \mathrm{~kg})$ weight per level of cervical injury and increase by $5-10$ pounds $(2.3-4.5 \mathrm{~kg})$ every $5-15 \mathrm{~min}$ $[2,4,5]$. Various maximal weights, up to $80 \%$ of the patient's body weight have been reported [2, 4, 5, 11-13]. In one study, the maximal weight used was 150 pounds $(68 \mathrm{~kg})$ [12].

Despite its numerous advantages, the use of skull tongs must be performed with caution as the surgeon has little or no control over the cervical vertebrae at the moment of disengagement. Thus, the potential disadvantages are overdistraction, tong pull-out, increasing pain and worsened neurologic deficits $[2,4,5,7]$. Other potential complications during the patient's in-hospital course while in traction are skull penetration, tong-site sepsis, osteomyelitis, and penetrating brain injury with extradural, subdural, or intracerebral haematoma $[1,2,4,5,7,16,17]$. Appropriate techniques in inserting the GWT may mitigate these complications. The complications of prolonged immobilisation, such as pressure sores, orthostatic pneumonia, autonomic dysfunction, deep vein thrombosis, urinary tract infection, etc, could also occur in patients on cervical traction. Thus, patients with CSI require a holistic approach to their management and rehabilitation. While we practice a holistic model of care in our centre, and some other centres in Nigeria, post-hospitalisation rehabilitation is often problematic as there are no dedicated spinal injury rehabilitation centres in the country.

The use of closed traction reduction of CSIs has been reported in various parts of Africa, with differing reported outcomes and effectiveness [18-23]. In our neurological surgery service, established in 1962, CSIs are managed mainly by closed reduction using Crutchfield's calipers (before 1988) and GWT (after 1988) traction. The patients may be maintained on traction for long periods (6-10 weeks) or have operative stabilisation if they can afford surgery. In the absence of regular fluoroscopy service, our closed traction reductions are routinely done under $\mathrm{X}$-ray film guidance. The effectiveness, outcome, and complications of the technique, as practiced in our centre for decades, have not been previously documented. This study was, thus, designed to determine the outcome of closed reduction of CSIs using GWT traction under X-ray film guidance in our patients.

\section{Methods}

We prospectively reviewed all consecutive CSI managed with closed reduction using the Gardener-Wells traction over a 3-year period (February 2012 to February 2015). Ethical approval was obtained from the institution's ethical committee. Patients with CSI managed conservatively or operatively without GWT insertion and traction were 
excluded from the study. Patients were enrolled on admission. The data collected for this study included their demography, presenting symptoms and duration, aetiology, diagnosis, X-ray findings (pre-, intra-, and post-traction reduction), bony and neurologic level of injury (pre- and post-traction reduction), Frankel grading (pre- and posttraction reduction), interval between injury and traction, weight to achieve maximal reduction, complications of closed reduction and of traction use. The degree of displacement on X-ray or computed tomography scan was graded as $<25 \%, 25-50 \%, 50-75 \%$, and $75-100 \%$.

\section{Intervention technique}

The technique of GWT insertion was uniform. Previously sterilised tongs were inserted under strict aseptic technique at the bedside using $2 \%$ Lignocaine local anaesthesia. The tongs were inserted in neutral position on either side about $4 \mathrm{~cm}$ or two finger breaths above the pinna. Slight variations in position about $2 \mathrm{~cm}$ anterior or posterior to the neutral site were accepted, for suspected flexion and extension injuries, respectively. The maintenance traction weight was $1-2 \mathrm{~kg}$ per level of cervical injury. Closed traction reduction was done in the central X-ray suite under close supervision by a doctor not below the rank of Junior Resident. Serial X-ray images were obtained with incremental traction weights of $5 \mathrm{~kg}$, which was left for about 10-20 min before the spine was imaged. This allowed adequate traction and relaxation of the muscles and ligaments. Reduction was discontinued if there was satisfactory vertebral realignment, worsening pain or neurologic deficits, or new-onset pain or neurologic deficits. Following satisfactory reduction (deemed as reduction up to $95 \%$ or more), the weight was reduced to the maintenance range, the lower value being preferred. The radiographic assessment pre and post traction were done by a neuro-radiologist.

\section{Outcome measures}

The primary outcome measures were extent/degree of reduction (based on percentage linear/translational motion of adjacent vertebrae) and neurologic status following closed reduction (using the motor and sensory levels of injury). The Frankel grading (pre- and post-reduction) were also quantified, and were classified as improved, same, or worse. Secondary outcome measures were the complications of closed reduction and GWT traction use. The reasons for failed reduction were noted.

\section{Limitations of our study}

Our study was conducted in a tertiary hospital with limited bed spaces reserved for spinal injuries. Many patients with these injuries could not be admitted and managed, and were referred to other centres. In addition, we utilised the Frankel grading rather than the International Standard for the Neurologic Classification of Spinal Cord Injuries (ISNCSCI) because we lack the resources needed to perform the ISNCSCI in our centre.

\section{Results}

Seventy-four patients with CSI underwent GWTs traction reduction over the study period. The mean age of the patients was 35.2 (standard deviation 9.7) years and 66.2\% (49) of them were males (Table 1). Aetiology was primarily motor vehicular accidents (74.3\%) and most (48.6\%) of these were passengers (Table 2).

Most patients complained of neck pain (94.6\%). Many (78.4\%) presented within 3 days of injury, with only $31.1 \%$ presenting within $24 \mathrm{~h}$ of injury. The majority of patients had anterior subluxation (86.5\%). Of the patients, $48.6 \%$

Table 1 Age and gender distribution

\begin{tabular}{lc}
\hline Variable & Total, $N=74(n / N, \%)$ \\
\hline Age group (years) & \\
$\leq 20$ & $4(5.4)$ \\
$21-30$ & $24(32.4)$ \\
$31-40$ & $28(37.8)$ \\
$41-50$ & $14(18.9)$ \\
$>50$ & $4(5.4)$ \\
Gender & \\
Male & $49(66.2)$ \\
Female & $25(33.8)$ \\
\hline
\end{tabular}

Table 2 Aetiology of CSI

\begin{tabular}{llc}
\hline Aetiology & Number of patients & Percentage (\%) \\
\hline Motor vehicular accident & 55 & 74.3 \\
Driver & 11 & 14.9 \\
Passenger & 36 & 48.6 \\
Pedestrian & 3 & 4.1 \\
Status not stated & 5 & 6.8 \\
Motorcycle accident & 8 & 10.8 \\
Driver/rider & 3 & 4.0 \\
Passenger & 4 & 5.4 \\
Pedestrian & 0 & 0 \\
Status not stated & 1 & 1.4 \\
Falls & 8 & 10.8 \\
Others & 3 & 4.1 \\
Total & 74 & 100 \\
\hline
\end{tabular}


Table 3 Bony level of injury and interval to reduction

\begin{tabular}{lc}
\hline Variable & $n / N(\%)$ \\
\hline Bony level of injury & \\
C1 & $2(3 \%)$ \\
C2 & $1(1 \%)$ \\
C3 & $3(4 \%)$ \\
C4 & $19(26 \%)$ \\
C5 & $20(27 \%)$ \\
C6 & $21(28 \%)$ \\
C7 & $8(11 \%)$ \\
Total & $74(100.0)$ \\
Interval to reduction & \\
$<24$ h & $1(1.4)$ \\
$1-3$ days & $14(18.9)$ \\
$4-7$ days & $20(27.0)$ \\
$>7$ days & $39(52.7)$ \\
Total & $74(100.0)$ \\
\hline
\end{tabular}

had less than $25 \%$ displacement, $25.7 \%$ had $25-50 \%$ displacement, $10.8 \%$ had $50-75 \%$ displacement, and $14.9 \%$ had more than $75 \%$ displacement.

The interval to reduction from time of accident was $>7$ days for about half of the patients $(52.7 \%)$ (Table 3). The reduction weight ranged from $2 \mathrm{~kg}$ to $60 \mathrm{~kg}$, with the highest average weight used being $33.9 \mathrm{~kg}$ (at $\mathrm{C} 6$ bony level) and the lowest being $2 \mathrm{~kg}$ (at both $\mathrm{C} 1$ and $\mathrm{C} 2$ bony levels) as shown in Fig. 1. The majority of patients (67.6\%) had a satisfactory extent of reduction (Fig. 2). Moreover, there were no patients with neurological deterioration posttraction and 14 patients (18.9\%) had improved neurological status post-traction (Table 4). More than half of the patients $(62.2 \%)$ had complete realignment. The majority of patients (85\%) had no complications while one patient had skull perforation.

The extent of reduction was not significantly associated with age, gender, neck pain, motor deficits, sphincter dysfunction, duration of symptoms, nature of injury, degree of displacement at presentation, and interval to reduction (Table 5). The only variable that was significantly associated with outcome post-traction was traction reduction weight. Weights $\leq 20 \mathrm{~kg}$ resulted in improved neurological status post-traction as compared with weights $>20 \mathrm{~kg}(p=$ 0.022) (Table 6).

Variables, which were associated with extent of traction reduction at $10 \%$ level of significance, were further analysed by logistic regression. The weight with the most satisfactory traction reduction was between $11 \mathrm{~kg}$ and $30 \mathrm{~kg}$ $(p=0.004)$. Reduction weights between $11 \mathrm{~kg}$ and $30 \mathrm{~kg}$ were approximately nine times more likely to have

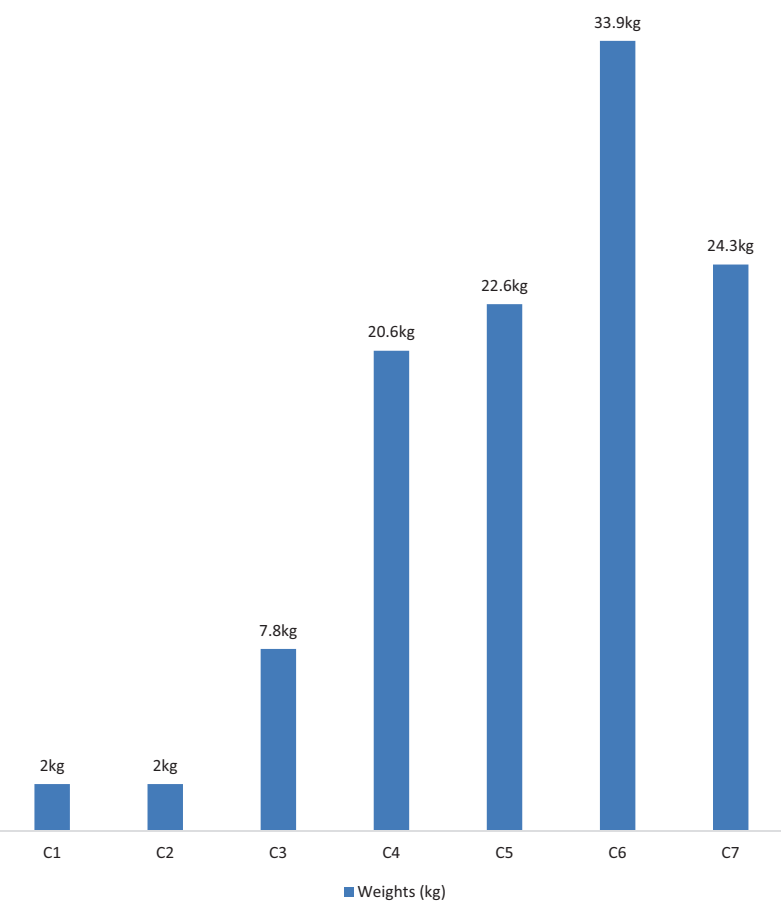

Fig. 1 Average weight for each bony level of traction reduction

satisfactory reduction than weights $>30 \mathrm{~kg}$ [odds ratio 8.99 (confidence interval 2.04-39.50)]. Patients who reported no sensory deficit had more satisfactory traction reduction than those who reported sensory deficit $(p=0.05)$.

\section{Discussion}

This study examines the effectiveness of closed traction reduction of CSI using the GWT traction in the current era in a Nigerian tertiary hospital. Successful traction was noted using the extent of reduction and the post-traction neurologic status.

The mean age and the male preponderance in this series are similar to other studies on CSI [4, 12, 20, 22, 23]. One of such studies found an average age of 42 years and males accounted for $76.8 \%$ of the patients [4]. In another study, the average age was 44 years and men were twice affected than women [24]. Other studies from Nigeria found average ages of 32.6 ( \pm 1.9 years) to 40.1 ( \pm 1.1 years) $[20,22,23$ ]. Young adult males are more likely to be involved in road traffic accidents (sustaining various injuries including CSI) because they are more mobile, adventurous, and more likely to be involved in sporting activities. The aetiology in this study is similar to previous studies though injuries from motorcycle accidents and passenger injuries were higher compared with prior studies. In similar studies, motor vehicular accidents accounted for $50-64.7 \%$ of the patients among which passengers accounted for 22-23.5\% $[4,13,24]$. 
Fig. 2 a, b Cervical spine X-rays showing $25 \%$ C5 on

C6 subluxation with satisfactory reduction on closed traction. $\mathbf{c}, \mathbf{d}$ Cervical spine $\mathrm{X}$-rays showing $20 \%$ C6 on C7 subluxation and angulation with satisfactory reduction on closed traction
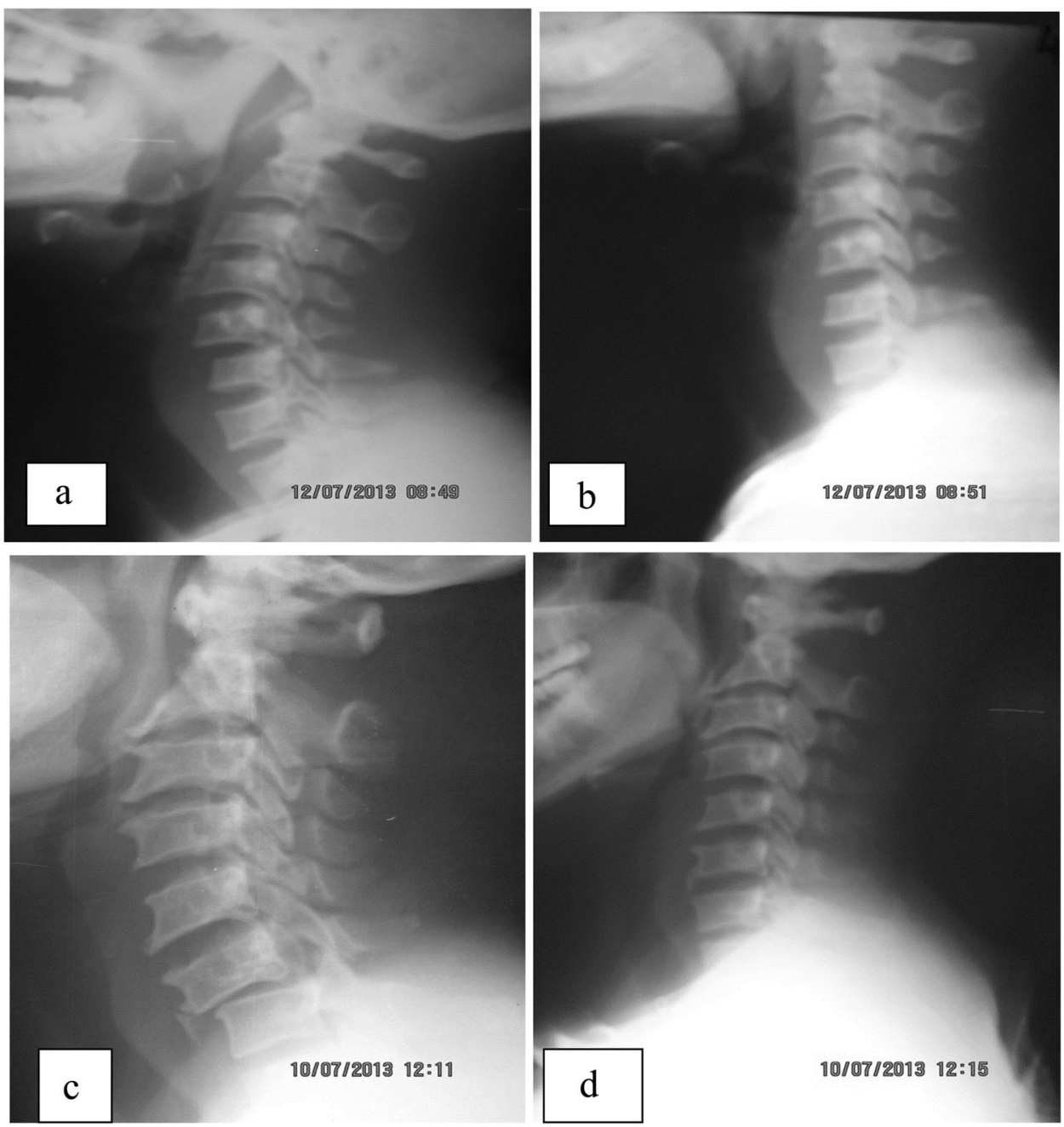

Table 4 Neurological status pre and post-traction

\begin{tabular}{|c|c|c|c|c|c|c|}
\hline \multirow{2}{*}{$\begin{array}{l}\text { Pre-traction } \\
\text { neurological } \\
\text { status (Frankel } \\
\text { grading) }\end{array}$} & \multicolumn{6}{|c|}{ Post-traction neurological status (Frankel grading) } \\
\hline & A & B & $\mathrm{C}$ & $\mathrm{D}$ & $\mathrm{E}$ & Total \\
\hline A & 38 & & 1 & & & 39 \\
\hline $\mathrm{B}$ & & 5 & 2 & 2 & & 9 \\
\hline $\mathrm{C}$ & & & 3 & 1 & & 4 \\
\hline $\mathrm{D}$ & & & & 4 & 8 & 12 \\
\hline $\mathrm{E}$ & & & & & 10 & 10 \\
\hline Total & 38 & 5 & 6 & 7 & 18 & 74 \\
\hline
\end{tabular}

Neck pain was the most common complaint among the patients $(94.6 \%)$. Most $(78.4 \%)$ of the patients presented within $72 \mathrm{~h}$ of injury, with $31.1 \%$ presenting within $24 \mathrm{~h}$. In other studies, the majority $(76.5 \%)$ presented within $24 \mathrm{~h}$ of injury [13]. The possible reasons for late presentation by the patients include lack of organised emergency rescue and ambulance services, poor road network, and few neurosurgical/spinal services. Poverty and ignorance are rampant among many patients and their care-givers, causing them to seek the services of traditional or alternative care providers at the initial instance.

The nature of injury has been variously classified by different authors $[3,4,7,13]$. Lower CSIs are reportedly more prevalent than upper cervical injuries. Thus, a higher proportion of our patients had the bony level of their injuries at C6 (28\%), C5 (27\%), and C4 (26\%) (Table 3). This is similar to another study where the main injury bony levels were C5-6 (35\%), and C6-7 (35\%) [13]. In the series by Hofmeister et al., lower CSIs were more prevalent (65.98\%) being more at C6/7 (24.4\%) and C5/6 (19.24\%) [24].

There is no consensus on the exact average weight to be used for initial traction reduction or maintenance traction [12]. The reduction weight in our series ranged from $2 \mathrm{~kg}$ to $60 \mathrm{~kg}$, with the highest average weight (used at C6 bony level) being $33.9 \mathrm{~kg}$ and the lowest average weight (used at $\mathrm{C} 1$ and $\mathrm{C} 2$ bony levels) being $2 \mathrm{~kg}$. Some researchers begin 
Table 5 Association between extent of reduction and other variables

\begin{tabular}{|c|c|c|c|c|c|}
\hline \multirow[t]{2}{*}{ Variable } & \multicolumn{2}{|l|}{ Extent of reduction } & \multirow[t]{2}{*}{$t$-test } & \multirow[t]{2}{*}{$p$-Value } & \\
\hline & Satisfactory & Not satisfactory & & & \\
\hline Mean age (years) & $36.5 \pm 9.9$ & $32.5 \pm 8.9$ & 0.040 & 0.103 & \\
\hline \multirow[t]{2}{*}{ Variables } & \multicolumn{2}{|l|}{ Extent of reduction } & \multirow[t]{2}{*}{ Total, $N(\%)$} & \multirow[t]{2}{*}{$\chi^{2}$} & \multirow[t]{2}{*}{$p$-Value } \\
\hline & Satisfactory, $n(\%)$ & Not satisfactory, $n(\%)$ & & & \\
\hline \multicolumn{6}{|l|}{ Gender } \\
\hline Male & $31(63.3)$ & $18(36.7)$ & $49(100.0)$ & & \\
\hline Female & $19(76.0)$ & $6(24.0)$ & $25(100.0)$ & 1.225 & 0.268 \\
\hline Neck pain & & & & & Fisher's exact $=0.097$ \\
\hline Yes & $49(70.0)$ & $21(30.0)$ & $70(100.0)$ & & \\
\hline No & $1(25.0)$ & $3(75.0)$ & $4(100.0)$ & 3.497 & \\
\hline Motor deficit & & & & & Fisher's exact $=0.527$ \\
\hline Yes & $39(65.0)$ & $21(35.0)$ & $60(100.0)$ & & \\
\hline No & $11(78.6)$ & $3(21.4)$ & $14(100.0)$ & 0.954 & \\
\hline \multicolumn{6}{|l|}{ Sensory deficit } \\
\hline Yes & $21(56.8)$ & $16(43.2)$ & $37(100.0)$ & & \\
\hline No & $29(78.4)$ & $8(21.6)$ & $37(100.0)$ & 3.947 & $0.047 *$ \\
\hline \multicolumn{6}{|c|}{ Sphincter dysfunction } \\
\hline Yes & $28(63.6)$ & $16(36.4)$ & $44(100.0)$ & & \\
\hline No & $22(73.3)$ & $8(26.7)$ & $30(100.0)$ & 0.765 & 0.382 \\
\hline \multicolumn{6}{|c|}{ Duration of symptoms } \\
\hline$\leq 24 \mathrm{~h}$ & $15(65.2)$ & $8(34.8)$ & $23(100.0)$ & & \\
\hline$>24 \mathrm{~h}$ & $35(68.6)$ & $16(31.4)$ & $51(100.0)$ & 0.084 & 0.793 \\
\hline Nature of injury & & & & & Fisher's exact $=0.484$ \\
\hline Subluxation & $42(65.5)$ & $22(34.4)$ & $64(100.0)$ & & \\
\hline Retrolisthesis & $8(80.0)$ & $2(20.0)$ & $10(100.0)$ & 0.816 & \\
\hline \multicolumn{6}{|c|}{ Degree of displacement } \\
\hline$\leq 50 \%$ & $39(70.9)$ & $16(29.1)$ & $55(100.0)$ & & \\
\hline$>50 \%$ & $11(57.9)$ & $8(42.1)$ & $19(100.0)$ & 1.091 & 0.296 \\
\hline \multicolumn{6}{|c|}{ Reduction weight } \\
\hline$\leq 10 \mathrm{~kg}$ & $12(75.0)$ & $4(25.0)$ & $16(100.0)$ & & \\
\hline $11-30 \mathrm{~kg}$ & $22(81.5)$ & $5(18.5)$ & $27(100.0)$ & & \\
\hline$>30 \mathrm{~kg}$ & $6(33.3)$ & $12(66.7)$ & $19(100.0)$ & 11.944 & $0.003 *$ \\
\hline \multicolumn{6}{|c|}{ Interval to reduction } \\
\hline$\leq 7$ days & $27(77.1)$ & $8(22.9)$ & $35(100.0)$ & & \\
\hline$>7$ days & $23(59.0)$ & $16(41.0)$ & $39(100.0)$ & 2.779 & 0.136 \\
\hline
\end{tabular}

*Statistically significant

traction with 3 pounds $(1.4 \mathrm{~kg})$ per level of cervical injury, increasing by $5-10$ pounds $(2.3-4.5 \mathrm{~kg})$ every $5-15 \mathrm{~min}$ $[2,4,5]$. In one series, the maximum weight was $80 \%$ of the patient's body weight, whereas in another up to 150 pounds $(68 \mathrm{~kg})$ was used for a bilateral dislocation at $\mathrm{C} 3 / 4$ $[4,5,12]$. In all cases, the end point of traction was successful closed reduction and realignment of the cervical spine column or the development of complications like intractable pain, worsening neurologic status, over-distraction, or failed reduction $[2,4,5,12]$.
Because of the high prevalence of delayed hospital presentation in our patients, as well as socioeconomic difficulties in procuring funds for investigations and treatment, the time interval from injury to traction reduction was over 7 days in more than half $(52.7 \%)$ (Table 3 ). In another study, the time interval ranged from $6 \mathrm{~h}$ to 8 weeks [13]. Other causes of delayed commencement of traction in our locality include incessant power outages, non-available or faulty equipment/facilities, and an overwhelming number of patients for an already over-stretched work force. 
Table 6 Association between neurological status post-traction and other variables

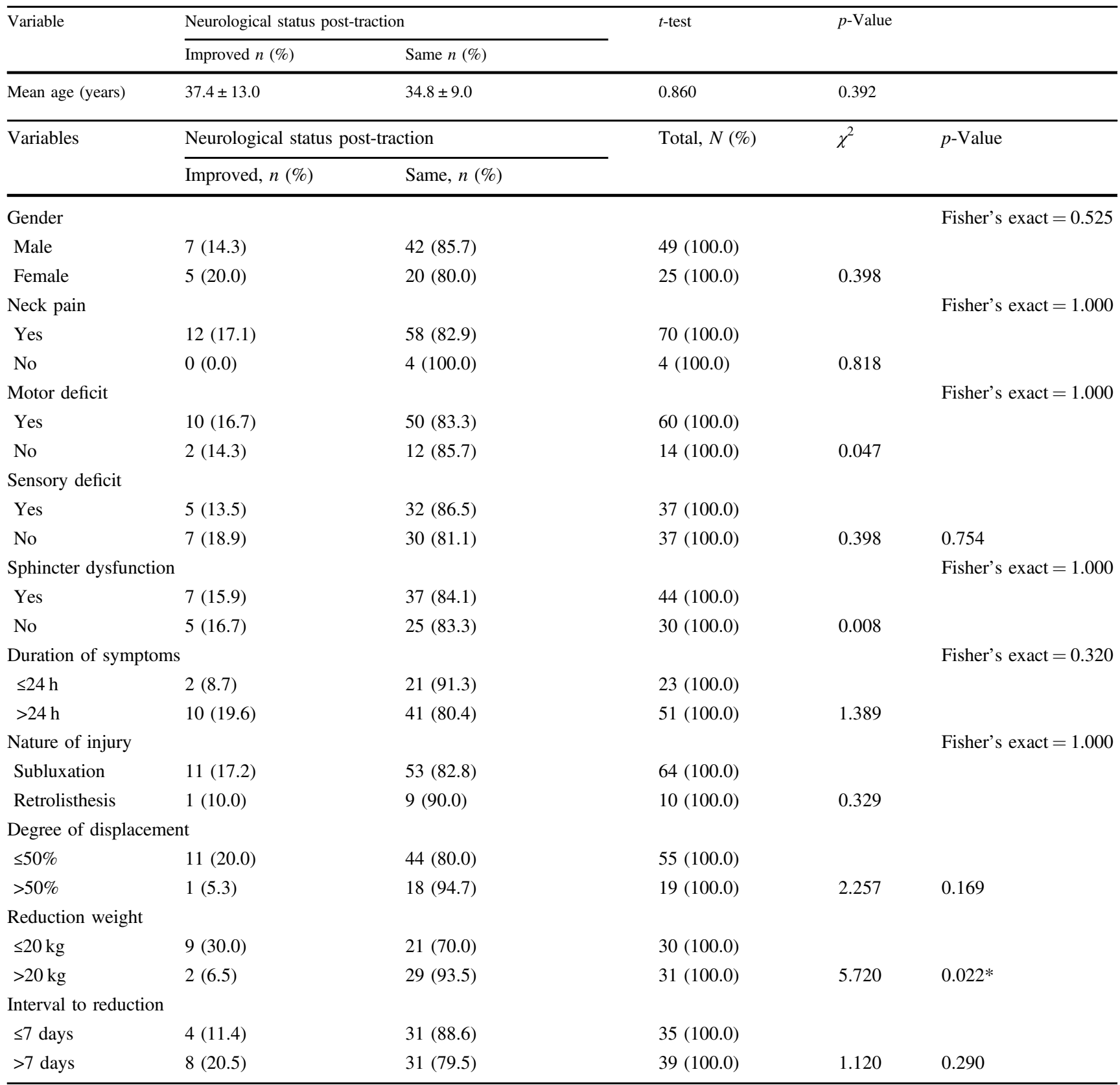

*Statistically significant

We achieved satisfactory extent of reduction in $67.6 \%$ of our patients, with $18.9 \%$ having improved neurologic status while none deteriorated. This is similar to other studies where the rate of successful closed traction was 58\% to $97.6 \%$, and neurologic improvement noted in $43.6 \%$ to $78 \%$ $[2,4,12,13,15]$. In these studies, the rate of neurologic deterioration was $1.3 \%$ to $11 \%[2,4,13]$. The American Association of Neurological Surgeons (AANS) metaanalysis of closed traction reduction studies showed approximately $80 \%$ successful reductions, $2.4 \%$ transient neurologic injuries, and about $1 \%$ permanent neurologic injuries [5]. The significant rate of failed reduction in our series can be attributed to the delayed presentation and commencement of the closed traction reduction in a significant proportion of our patient population in this study. Up to $10.8 \%$ thus probably failed because their injury was so old (Fig. 3). Other causes of failed reduction were: facet lock $(20.3 \%)$, worsening pain $(4.1 \%)$, and over-distraction (2.7\%). The reported causes of failed closed traction reduction in other studies include those already cited, as 
Fig. 3 a, b Cervical spine X-rays showing $50 \%$ C5 on

C6 subluxation with angulation and bilateral facet lock, which failed on closed reduction. $\mathbf{c}, \mathbf{d}$ Cervical spine $\mathrm{X}$-rays showing $100 \%$ C5 on C6 retrolisthesis with $\mathrm{C} 5$ and $\mathrm{C} 6$ corporal fracture, which failed on closed reduction
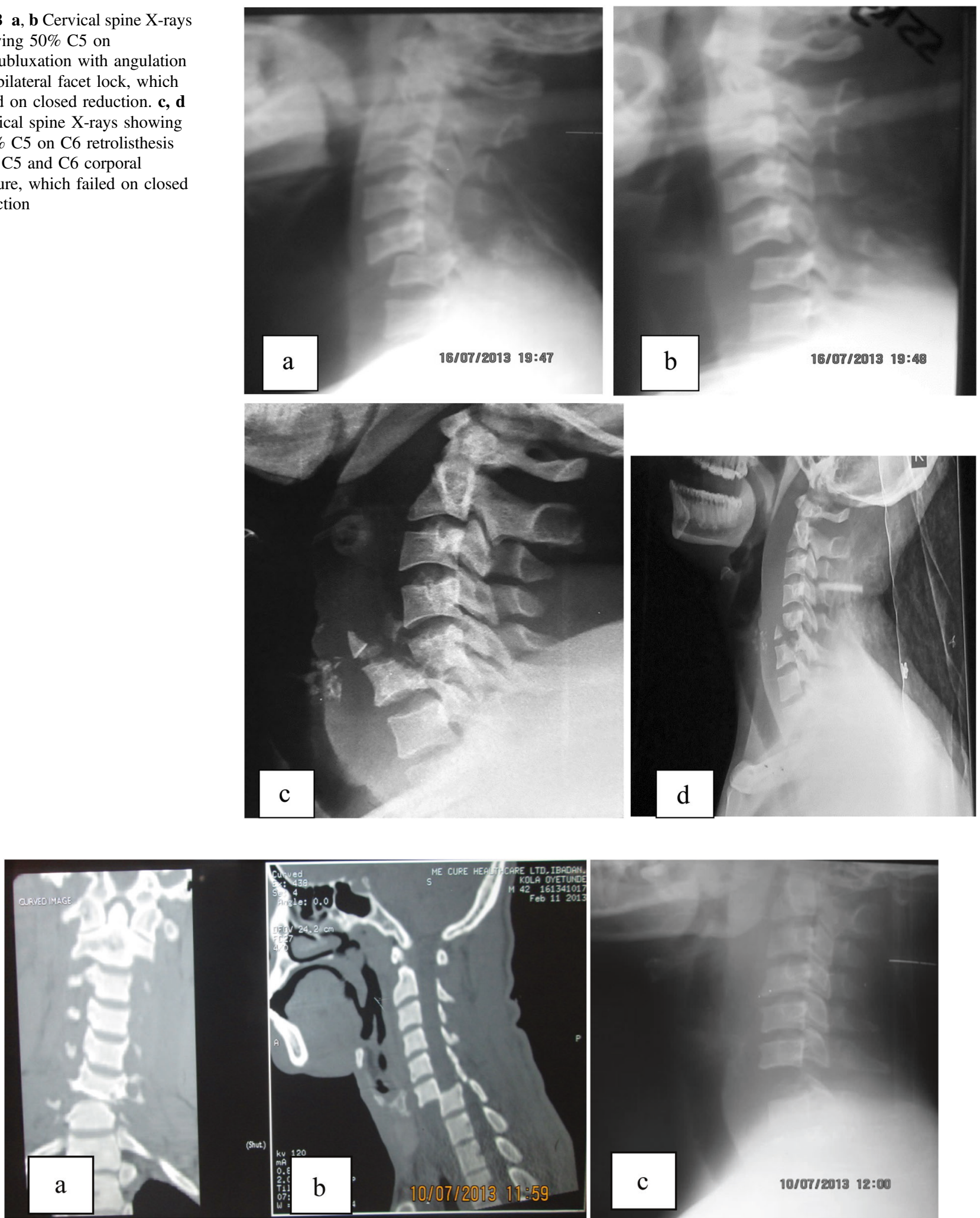

Fig. 4 a, b Cervical spine computed tomography scan showing $100 \%$ C6 on C7 subluxation. c Cervical spine X-ray of the patient in a and b showing complete reduction with over-distraction 
well as non-contiguous vertebral fracture at a more rostral level, facet fracture at the level of subluxation, worsening neurologic deficits, cervical disc herniation, epidural haematoma, cord oedema, arm weakness, tong pull-out, inadequate immobilisation, and poor patient status (cardiac, respiratory, and haemodynamic instability) $[2,4,5,8,12$, $14,15,17,18,22,25]$. The complications of closed traction reduction seen in our series were over-distraction (7\%) (Fig. 4 ), tong pull-out (3\%), new-onset/worsening pain (3\%), pin site infection (3\%), and skull perforation (1\%). These are known complications of skull tong use, and have been previously documented $[4,5,18,19]$.

Although, this study showed that satisfactory closed traction reduction was dependent on traction weights and absence of sensory deficits other studies have rather reported significant association between neurologic recovery and timing of reduction [2]. Early reduction/realignment/decompression within $8 \mathrm{~h}$ of injury is said to improve the likelihood of neurologic preservation [5]. Perhaps, this study might have found the same results but for the fact that very few patients had traction reduction within $24 \mathrm{~h}$ of injury compared with a larger number who had traction reduction after $24 \mathrm{~h}$; this made the groups non-comparable in terms of determinants of satisfactory closed traction reduction.

\section{Conclusion}

Satisfactory closed traction reduction with limited complications is feasible with GWT traction in many patients with CSI and significant vertebral malalignment. Neurologic outcome post-traction may be significantly associated with appropriate traction weight and presence or absence of sensory deficits.

\section{Compliance with ethical standards}

Conflict of interest The authors declare that they have no conflict of interest.

Publisher's note: Springer Nature remains neutral with regard to jurisdictional claims in published maps and institutional affiliations.

\section{References}

1. Drake CG. Cervical spinal cord injury. J Neurosurg. 1962;19:487-94.

2. Hadley MN, Fitzpatrick BC, Sonntang VKH, Browner CM. Facet fracture-dislocation injuries of the cervical spine. Neurosurgery. 1992;30:661-6.

3. Torretti JA, Sengupta DK. Cervical spine trauma. Indian J Orthop. 2007;41:255-67.
4. Grant GA, Mirza SK, Chapman JR, Winn HR, Newell DW, Jones DT, et al. Risk of early closed reduction in cervical spine subluxation injuries. J Neurosurg (Spine). 1999;90:13-8.

5. AANS/CNS Section on Spine and Peripheral Nerves. Initial closed reduction of cervical spine fracture-dislocation injuries. Neurosurgery. 2002;50:S44-S50.

6. Gallie WE. Fractures and dislocations of the cervical spine. Am J Surg. 1939;XLVI:495-9.

7. Lee JY, Nassr A, Eck JC, Vaccaro AR. Controversies in the treatment of cervical spine dislocation. Spine J. 2009;9:418-23.

8. Robertson PA, Ryan MD. Neurological deterioration after reduction of cervical subluxation. J Bone Jt Surg (Br). 1992;74B:224-7.

9. Abel R. Surgery for spinal injury with neurologic deficit: a matter of opinion?. Spinal Cord Ser Cases. 2018;4:16 https://doi.org/10. 1038/s41394-018-0048-9.

10. El Masri(y) WS. Traumatic spinal injury and spinal cord injury: point for active physiological conservative management as compared to surgical management. Spinal Cord Ser Cases. 2018;4:14. https://doi.org/10.1038/s41394-018-0045-z.

11. Evans DK. Reduction of cervical dislocations. J Bone Jt Surg (Br). 1961;43-B:552-5.

12. Lee AS, MacLean JCB, Newton DA. Rapid traction for reduction of cervical spine dislocations. J Bone Jt Surg (Br). 1994;76B:352-6.

13. Darsaut TE, Ashforth R, Bhargava R, Broad R, Emery D, Kortbeek $\mathrm{F}$, et al. A pilot study of magnetic resonance imaging-guided closed reduction of cervical spine fractures. Spine. 2006;31:2085-90.

14. Gallie WE. Skeletal traction in the treatment of fractures and dislocations of the cervical spine. Ann Surg. 1937;106:770-6.

15. Kleyn PJ. Dislocations of the cervical spine: closed reduction under anaesthesia. Paraplegia. 1984;22:271-81.

16. Kyoshima K, Kakizawa Y, Tokushige K. Simple cervical spine traction using a Halo vest apparatus: technical note. Surg Neurol. 2003;59:518-21.

17. Ludwig SC, Vaccaro AR, Balderston RA, Cotler JM. Immediate quadriparesis after manipulation for bilateral cervical facet subluxation. J Bone Jt Surg (Am). 1997;79-A:587-90.

18. du Toit AB, Dunn R. Bifacet dislocations of the cervical spine: acute management and outcome. SA Ortho J. 2008;30-6.

19. Emejulu JKC, Ekweogwu OC. Outcome of spinal cord injuries management in a centre without modern imaging facilities. West Afr J Med. 2009;28:376-9.

20. Eyichukwu GO, Anyaehie UC, Moghalu ON. Pattern and outcome of management for traumatic closed cervical spine injuries at the National Orthopaedic Hospital, Enugu, Nigeria. Nig Health J. 2011;11:27-31.

21. Nizare EF, Abdellah B, Fahd DH, Yassad OM, Rachid G, Rachid EM, et al. Upper cervical spine injuries: a management of a series of 70 cases. Pan Afr Med J. 2013;15:57.

22. Uche EO, Nwankwo OE, Okorie E, Nnezianya I. Cervical spine injury: a 10-year multicenter analysis of evolution of care and risk factors for poor outcome in South-East Nigeria. Nig J Clin Pract. 2015;18:203-8.

23. Uche EO, Nwankwo OE, Okorie E, Muobike A. Skull traction for cervical spine injury in Enugu: a 5-year retrospective multicenter analysis of the clinical outcomes of patients treated with two common devices. Nig J Clin Pract. 2016;19:580-4.

24. Hofmeister M, Jaksche H, Potulski M, Buhren V. Treatment of cervical spine injuries. Osteo Trauma Care. 2003;11:166-76.

25. Mahale YJ, Silver JR, Henderson NJ. Neurological complications of the reduction of cervical spine dislocations. J Bone Jt Surg (Br). 1993;75-B:403-9. 